\title{
Prevention of musculoskeletal neck disorders in echocardiographers
}

\author{
Alexander Kiško*, Pavol Nechvátal, Miriam Ištonová \\ Faculty of Health Care, Prešov University in Prešov, Prešov, Slovak Republic
}

Echocardiographic operators using the most traditional right handed scanning are five times more likely to be at risk from the back pain and almost a half of them are reporting neck musculoskeletal disorders (MSD). Painful posture leads to abnormal muscle contraction and a new pain. If the condition persists, it may cause organic disorders resulting in structural degenerative changes.

The aim of this pilot study was to develop on the basis of the physiotherapeutic analysis of the postures of 50 echocardiographers while providing scanning of simple preventive interventions that can be self-performed at the work places. Practice in a wrong posture characterized by a lateral shift of the trunk in the frontal plane, kyphotic holding of the thoracic spine, elevation of one or both arms, and outpost of the head with extension of its joints can result in overload of muscular and skeletal neck segments with tissue damage and discs protrusion, causing long lasting MSD.

Based on this, we have given the following recommendations. Firstly, it is about control of physiological posture that means to hold the torso upright with the correct position of

\section{Received: $17^{\text {th }}$ Apr 2014}

${ }^{*}$ Address for correspondence: Faculty of Health Care, Prešov University in Prešov, 0801 Prešov, Partizanska 1, Slovak Republic.

Phone: +421907439977

E-mail: alexander.kisko@unipo.sk the head, cervical spine and shoulders. It is not always possible to minimize lateral shift of the trunk in the frontal plane; therefore easy compensatory exercises are the most suitable. Secondly, simple relaxation exercises for the neck muscles performed in a defined position and direction and synchronized with breath are highly appropriate. They are quite effective for the restoring of the physiological length and tension of the muscles. Thirdly, a self performed massage is highly recommended additionally to reduce the increased muscle tension of the neck. It can be performed by one or two-handed spawning or kneading applications and resulting in an improving muscle blood supply, thus eliminating the pain that occurs on the basis of ischemia. The time required for the self-performing of the proposed preventive program does not exceed five minutes and it should be performed during the breaks between the examinations at least once per hour.

The next step of our initiative will be a practical application of the recommended preventive interventions. Furthermore, a well-constructed study at a large sonographic population is to be considered to properly test a proposed preventive program to confirm if it will reduce the reported MSD to which echocardiographers are susceptible.

KEYWORDS: musculosceletal disorders, echocardiographers, prevention.

CITATION: Cardiol Croat. 2014;9(5-6):186.

\section{Literature}

1. Macdonald K, King D. Work-related musculoskeletal disorders in veterinary echocardiographers: a cross-sectional study on prevalence and risk factors. $J$ Vet Cardiol. 2014;16(1):27-37.

2. Randall E, Hansen C, Gilkey D, et al. Evaluation of ergonomic risk factors among veterinary ultrasonographers. Vet Radiol Ultrasound. 2012;53(4):459-64.

3. Smith AC, Wolf JG, Xie GY, Smith MD. Musculoskeletal pain in cardiac ultrasonographers: results of a random survey. J Am Soc Echocardiogr. 1997;10(4):357-62. 